\title{
Retinal Vein Occlusion: Demography, Types and Risk Factors - A Cross-Sectional Hospital based Study
}

\section{Hara Maya Gurung, Eliya Shrestha, Babita Gurung, Hari Bikram Adhikari and Pawan Baral*}

Himalaya Eye Hospital, Pokhara, Nepal

*Corresponding Author: Pawan Baral, Himalaya Eye Hospital, Pokhara, Nepal.
Received: April 06, 2021

Published: April 23, 2021

(C) All rights are reserved by Hara Maya

Gurung., et al.

\begin{abstract}
Purpose: To assess the demographic pattern, types and risk factors of retinal vein occlusion disease of the patients visiting Himalaya Eye Hospital.

Methods: A cross-sectional observation study of 246 patients was done at Himalaya Eye Hospital, Pokhara, Nepal during the period from July 2017 to July 2020. All these patients were diagnosed with retinal vein occlusion during this period and were included in the study. Patients with associated complications such as vitreous hemorrhage and macular edema without retinal vein occlusion were excluded from the study.

Results: A total of 246 patients were diagnosed as a case of retinal vein occlusion disease during this study period. Age of the patients ranged from 29 to 87 years old with the mean age being $65.95( \pm 11.47)$ years. Elderly populations were found vulnerable to this disease. Total number of males (50.40\%) were slightly higher than females (49.59\%). Branch retinal vein occlusion (74.80\%) was observed to be three times more common than central retinal vein occlusion (25.20\%). Hypertension was detected as the most important risk factor for retinal vein occlusion disease followed by increase in age, combined hypertension and diabetes, dyslipidemia and smoking.

Conclusion: This hospital-based study of demographic pattern, types and risk factors of retinal vein occlusion would help us to target the specific population of community for awareness programme.
\end{abstract}

Keywords: CRVO; BRVO; Hypertension; Increase in Age

\section{Abbreviations}

BRVO: Branch Retinal Vein Occlusion; CRVO: Central Retinal vein Occlusion; CBC: Complete Blood Count; ESR: Erythrocyte Sedimentation Rate; FBS: Fasting Blood Sugar; FPL: Fasting Lipid Profile; FFA: Fundus Fluorescein Angiography; HEH: Himalaya Eye Hospital; RVO: Retinal Vein Occlusion

\section{Introduction}

Retinal vein occlusion (RVO) is an important ocular blinding condition second to diabetic retinopathy [1]. It is more common among men than women and in age above 65 years old. RVO is broadly classified as central retinal vein occlusion (CRVO) and branch retinal vein occlusion (BRVO) [2]. BRVO in which a branch of retinal vein is occluded is 4 to 6 times more common than CRVO, where occlusion occurs in the central retinal vein. The disease oc- 
curs as a result of three systemic combination known as Virchow's triad- hemodynamic changes (venous stasis), degenerative changes in the vessel wall and blood hypercoagulability [3]. Hypertension is considered as the most important risk factors for RVO followed by other factors like advanced age, diabetes, raised serum lipids, lack of physical activity and smoking [4,5].

The purpose of this study is to have a general idea about the demographic pattern, types of RVO and the associated risk factors for causing this disease among the patients visiting Himalaya Eye Hospital ( $\mathrm{HEH})$. Based on the findings we can conduct eye health awareness programme in the targeted group of the community.

\section{Materials and Methods}

This is a hospital based cross-sectional observation study conducted from July 2017 to July 2020. 246 patients diagnosed with RVO during this period at HEH, Pokhara, Nepal are included in the study. A written informed consent was taken from all the patients before enrollment in the study.

Inclusion criteria: All patients diagnosed with retinal vein occlusion.

Exclusion criteria: Patients with lenticular opacity preventing fundus evaluation, vitreous hemorrhage, macular edema without associated vein occlusion disease.

Procedure: For all the participants a detailed history about the symptoms, medical history, personal history and demography was taken. Unaided and best corrected Snellen visual acuity was recorded. Slit lamp (Zeiss) biomicroscopy examination of anterior segment and 1\% tropicamide dilated fundus examination using 90 D Volk lens was done. Intraocular pressure was recorded using non-contact air puff tonometer (Topcon CT-800). Macular Optical coherence tomography (Zeiss Cirrus HD-OCT 4000) and Fundus fluorescein angiography (FFA) (Topcon TRC-NW8F) was done as indicated. Hypertension was labeled if the systolic pressure was $>160 \mathrm{mmHg}$ and diastolic pressure was $>90 \mathrm{mmHg}$ or patient was on regular anti-hypertensive medications. Laboratory tests were evaluated for complete blood count (CBC), fasting blood sugar (FBS), fasting lipid profile (FLP), erythrocyte sedimentation rate (ESR) and serum homocysteine level (if necessary). Cardiac consultation along with ECHO, ECG and carotid doppler was advised. Any cardiac problems like valvular heart disease, congestive car- diac failure or past history of myocardial infarction were labeled as heart disease.

\section{Data collection and statistical analysis}

The data was initially collected in the standard form developed for the study. The form included variables for patients' demographic details including age, gender, ethnicity, eye, pattern of RVO and associated risk factors. The data collected in the forms was then entered in the Microsoft Excel 2013 and analyzed in same.

\section{Results}

Demographic pattern

A total of 246 eligible patients diagnosed with RVO were included in the study during this study period. The patients' age ranged from 29 to 87 years old with the mean age of $65.95( \pm 11.47)$ years. RVO was seen more common among the patients with the age ranging from 61 to 80 years old. The number of males (50.40\%) were slightly higher than females (49.59\%). Regarding ethnicity, patients with Brahmin caste got affected most (30.89\%) with RVO followed by Mongolians (24.39\%) (Table 1).

\begin{tabular}{|l|c|c|c|}
\hline & BRVO & CRVO & Total Subjects \\
\hline Age & \multicolumn{3}{|l|}{} \\
\hline$\leq 40$ & 3 & 2 & 5 \\
\hline $41-50$ & 19 & 2 & 21 \\
\hline $51-60$ & 43 & 13 & 56 \\
\hline $61-70$ & 52 & 16 & 68 \\
\hline $71-80$ & 54 & 19 & 73 \\
\hline$>80$ & 13 & 10 & 23 \\
\hline Sex & \multicolumn{3}{|l}{} \\
\hline Male & 89 & 35 & 124 \\
\hline Female & 95 & 27 & 122 \\
\hline Ethnicity & \multicolumn{3}{|l}{} \\
\hline Brahmin & 61 & 15 & 76 \\
\hline Chhetri & 35 & 7 & 42 \\
\hline Mongolian & 42 & 18 & 60 \\
\hline Newar & 40 & 13 & 53 \\
\hline Others & 6 & 9 & 15 \\
\hline $\begin{array}{l}\text { Diagnosis } \\
\text { Total (\%) }\end{array}$ & 184 & 62 & $246(100 \%)$ \\
\hline
\end{tabular}

Table 1: Demographic information of RVO.

RVO: Retinal Vein Occlusion; BRVO: Branch Retinal Vein Occlusion; CRVO: Central Retinal Vein Occlusion. 


\section{Types of RVO}

Based on the number and types of retinal vein occlusion presenting at $\mathrm{HEH}$, the subjects were found three times more likely to have BRVO (74.80\%) than CRVO (25.20\%) (Table 1). Among the patients diagnosed with BRVO, Superotemporal BRVO was found to be the most common (74.45\%). Right eye was more affected in both the BRVO (52.7\%) and CRVO (71\%) group whereas $5.5 \%$ of patients in BRVO group got both the eyes affected (Table 2).

\begin{tabular}{|l|c|c|c|c|}
\hline & Right Eye & Left Eye & Bilateral & Total \\
\hline BRVo & & & & \\
\hline Superotemporal & 76 & 52 & 9 & 137 \\
\hline Inferotemporal & 18 & 20 & 1 & 39 \\
\hline Macular & 1 & 3 & 0 & 4 \\
\hline Hemiretinal & 2 & 2 & 0 & 4 \\
\hline Total (\%) & 97 & 77 & $10(5.5 \%)$ & 184 \\
$(52.7 \%)$ & $(41.8 \%)$ & $100 \%)$ \\
\hline CRVO & 44 & 18 & 0 & 62 \\
\hline Total (\%) & $44(71 \%)$ & $18(29 \%)$ & $0(0 \%)$ & $62(100 \%)$ \\
\hline
\end{tabular}

Table 2: Pattern of RVO and laterality.

RVO: Retinal Vein Occlusion; BRVO: Branch Retinal Vein Occlusion; CRVO: Central Retinal Vein Occlusion.

\section{Risk factors for causing RVO}

Hypertension was considered the most important risk factor in both the BRVO (32\%) and CRVO (41.93\%) patients. Combined hypertension and diabetes were nearly equally seen in both BRVO (10.32\%) and CRVO (9.67\%) patients. Primary open angle glaucoma was seen as an important ocular risk factor for causing CRVO (16.12\%). Most patients in the study had the habit of smoking and alcohol consumption which contributed as a risk factor for the RVO (Table 3).

\section{Discussion}

RVO disease is the second most common retinal disease after diabetic retinopathy [3]. This study done at HEH, Pokhara, Nepal enrolled a total of 246 patients diagnosed with RVO disease whose demographic pattern, types and risk factors for causing the disease were studied. BRVO was found more among elderly patients ranging from 61 to 80 years of age. The pathogenesis in BRVO being the arterial stiffness which increases with age and causes venous compression in common adventitial sheath [3]. Females suffered

\begin{tabular}{|l|c|c|}
\hline Glaucoma & $\begin{array}{c}\text { No. of patients in } \\
\text { BRVO (\%) }\end{array}$ & $\begin{array}{c}\text { No. of patients in } \\
\text { CRVO (\%) }\end{array}$ \\
\hline POAG & & $10(16.12 \%)$ \\
\hline $\begin{array}{l}\text { Systemic } \\
\text { Diseases }\end{array}$ & $59(32 \%)$ & $26(41.93 \%)$ \\
\hline HTN & $19(10.32 \%)$ & $6(9.67 \%)$ \\
\hline DM & $19(10.32 \%)$ & $6(9.67 \%)$ \\
\hline HTN+DM & $2(1.08 \%)$ & \\
\hline HD & $12(6.52 \%)$ & $5(8.06 \%)$ \\
\hline HL & $46(25 \%)$ & $15(24.19 \%)$ \\
\hline Personal Habits & $15(8.15 \%)$ & $4(6.45 \%)$ \\
\hline Smoking & $14(7.60 \%)$ & $4(6.45 \%)$ \\
\hline Alcohol & & \\
\hline $\begin{array}{l}\text { Smoking + } \\
\text { Alcohol }\end{array}$ & & \\
\hline
\end{tabular}

Table 3: Ocular and systemic risk factors associated with RVO. POAG: Primary Open Angle Glaucoma; HTN: Hypertension; DM:

Diabetes Mellitus; HD: Heart Disease; HL: Hyperlipidaemia.

more from BRVO than males whereas CRVO was seen more among males in our study in contrast to the study done by Archana., et al. [4] where both BRVO and CRVO were more in males than females. Patients belonging to Brahmin ethnicity were the most vulnerable group, a findings similar to a hospital based case-control study done by Thapa R., et al [2]. A study done in Malaysia however showed no significant ethnic distribution of RVO [6].

BRVO was found three times more common than CRVO in our study which is comparable to a study carried out in India by Archana., et al [4]. Likewise, superotemporal was the retinal vein branch most affected in BRVO. An opinion commonly shared by other studies $[2,7]$. The cause for the location of BRVO predominantly at the temporal retina is the presence of larger retinal arteries and veins at the superior temporal and inferior temporal vascular arcades than the superior nasal and inferior nasal vascular arcades and more arteriovenous crossings at the superotemporal quadrant of retina [5].

Primary open angle glaucoma (POAG) was detected as an important ocular risk factor for CRVO which is comparable with other studies done in Nepal [2,7]. Among the systemic risk factors, hy- 
pertension was found the most common factor observed in both BRVO (32\%) and CRVO (41.93\%) patients in our study (Table 3). It is found to be in accordance with previous studies [2,4]. The other systemic risk factors observed were the presence of diabetes, combined diabetes and hypertension, heart disease and dyslipidemia. They were found more common among patients who suffered from BRVO than CRVO. The reason could be the incidence of BRVO being more common than CRVO.

\section{Conclusion}

With the increase in life expectancy and change in life styles more people are suffering from hypertension and diabetes which has a deleterious effect on ocular health too. They act as risk factors for retinal vein occlusion disease. Personal habit like cigarette smoking is also found to increase the risk of RVO. So, this hospital-based study of demographic pattern, types and risk factors of retinal vein occlusion helped us to target the specific population of community for eye health awareness programme.

\section{Acknowledgements}

The authors would like to acknowledge the support provided by Himalaya Eye Hospital in conducting this study.

\section{Conflict of Interest}

None.

\section{Bibliography}

1. Rogers S., et al. "The prevalence of retinal vein occlusion: Pooled data from population studies from the United States, Europe, Asia and Australia". Ophthalmology 117 (2010): 313-319.

2. Thapa R., et al. "Demographic characteristics, patterns and risk factors for retinal vein occlusion in Nepal: a hospital-based case-control study". Clinical and Experimental Ophthalmology 38 (2010): 583-590.

3. Kolar P. "Risk factors for branch and central retinal vein occlusion: A meta-analysis of published clinical data". Journal of Ophthalmology (2014): 5.

4. K Archana and Radhika M. "Baseline characteristics and risk factors for retinal vein occlusions". International Journal of Contemporary Medical Research 6.3 (2019): C13-C16.

5. Zhou JQ., et al. "The 10-year incidence and risk factors of retinal vein occlusion". Ophthalmology 120 (2013): 803-808.
6. Teoh SL and Amarjeet K. "A comparative study of branch retinal vein occlusion and central vein occlusion amongst Malaysian patients". Medical Journal of Malaysia 48.4 (1993): 410-415.

7. Sherpa D., et al. "Association of primary glaucoma with retinal vein occlusion". Kathmandu University Medical Journal 6.21 (2008): 49-54.

\section{Assets from publication with us}

- Prompt Acknowledgement after receiving the article

- Thorough Double blinded peer review

- Rapid Publication

- Issue of Publication Certificate

- High visibility of your Published work

Website: www.actascientific.com/

Submit Article: www.actascientific.com/submission.php

Email us: editor@actascientific.com

Contact us: +919182824667 